\title{
Desmistificando o mito da turma homogénea: caminhos duma sala de aula inclusiva
}

Mário Rui Domingues Ferreira da Cruz*

\section{Resumo}

Neste artigo, procuraremos repensar a sala de aula e o seu funcionamento numa perspectiva de promoção de mudanças significativas com vista à inclusão. Neste sentido, optámos por analisar o processo de ensino-aprendizagem respeitante a apenas uma turma do sétimo ano de escolaridade duma escola secundária, no Grande Porto (Portugal), na qual leccionávamos Inglês como língua estrangeira (LE). Este artigo encontra-se dividido em 3 grandes partes que se referem a diferentes mas articuladas temáticas, nomeadamente: repensar a educação obrigatória no sentido da inclusão; a atenção à diversidade no processo de ensino-aprendizagem; e, ainda, o processo de ensino-aprendizagem e a gestão eficaz do tempo de ensino.

Palavras-chave: Inclusão. Métodos de ensino-aprendizagem. Gestão eficaz do ensino.

\section{Demystifying the myth of the homogeneous class: paths of an inclusive classroom}

\begin{abstract}
In this article, we aim to rethink the classroom and its organization with a view to promote significant changes towards inclusion. In this way, we chose to analyze the process of teaching and learning regarding one class of the seventh grade at a secondary school in Oporto (Portugal), in which we taught English as a Foreign Language (EFL). This article is divided into 3 main parts that refer to different but articulate themes, namely: rethinking compulsory education for inclusion, attention to diversity in the teaching-learning process and also the teaching process learning and effective management of teaching time.
\end{abstract}

Keywords: Inclusion. Teaching and learning methodologies. Effective teaching time management.

"Há escolas que são gaiolas e há escolas que são asas"

Rubem Alves

\footnotetext{
* Professor Assistente na Escola Superior de Educação de Paula Frassinetti/Investigador Centro de Investigação Didática e Tecnologia na Formação de Formadores (CIDTFF) - Departamento de Didática e Tecnologia Educativa, Universidade de Aveiro, Cacia, Portugal.
} 


\section{Introdução}

Recentemente, alguns autores como $\operatorname{HOLT}(1981$, p. 21) pintam um sistema de ensino saturado, onde existem professores que treinam as crianças para dizer as respostas que esperam e não fomentam uma auto-aprendizagem (cf. LYMAN, 1998, WEB).

Mais ainda, tendo em conta o contexto educativo actual, o professor tem que, por vezes, assumir funções de educador social, psicólogo, confidente e mesmo de pai. Neste momento, é solicitado a qualquer professor que dê resposta às necessidades de todos os alunos, uma vez que estes são todos "diferentes" na preparação para a vida adulta.

\section{Repensar a educação obrigatória no sentido da inclusão}

A igualdade de direitos na educação deve significar um trabalho de comunidade inclusivo, onde se tenha em conta os vários tipos de diversidade: género, classe, cultura e as variações na capacidade funcional. O processo educacional tem que ultrapassar a perspectiva sobre a vida e a linguagem da cultura dominante, para também incluir a perspectiva acerca da vida e as formas de expressão das culturas não dominantes. Neste contexto, preconiza-se que todos os alunos se sintam bem com o ambiente de ensino-aprendizagem e, concomitantemente, de experienciar que a sua origem, a sua língua e a sua identidade próprias são também aceites e respeitadas.

Refiro-me aqui a um processo de ensino-aprendizagem mais inclusivo do que apenas integrador, que se baseia nas seguintes crenças:

- todas as crianças conseguem aprender;

- todas as crianças frequentam salas de aula regulares adequadas à sua idade e recebem programas educativos adequados;

- todas as crianças têm um currículo relevante adequado às suas necessidades;

- todas têm a possibilidade de participar em actividades curriculares e extra-curriculares.

Resumindo, podemos afirmar que uma escola baseada num modelo inclusivo assenta numa planificação flexível e sistemática, tendo a escola que seguir uma filosofia inclusiva, dispor de recursos e apoios adequados e aplicar estratégias de intervenção e de avaliação adequadas.

\section{A atenção à diversidade no processo de ensino-aprendizagem}

Na verdade, a procura de métodos de ensino-aprendizagem eficazes tem sido a preocupação de didácticos, pedagogos e sociólogos nos últimos anos. O grande propósito desta interminável busca prende-se com o facto de se tentar estabelecer um tipo de ensino 
"capaz de adaptar-se, acolher e cultivar as diferenças com um elemento de valor positivo, e a abertura de um espaço pluralista e multicultural, no qual se mesclem as cores, os géneros, as capacidades [...]" (CAMACHO, 2003, p. 9).

\title{
2.1 A turma como grupo dinâmico e diverso
}

Para fomentar um processo de ensino-aprendizagem inclusivo, um professor deve começar por conhecer os seus alunos. Quando comecei a trabaIhar com a turma que é objecto de estudo neste trabalho, rapidamente a caracterizei como uma turma multicultural, já que tinha na mesma turma alunos de diferentes nacionalidades e etnias, nomeadamente: uma aluna cabo-verdiana, Raquel; ${ }^{1}$ dois alunos franceses, Angelina e Jamie; e, ainda, um aluno de etnia cigana, o Júlio. Contudo, longe estava de imaginar que a diversidade seria muito mais aprofundada do que a primeira impressão me tinha ensinado.

Esta turma é constituída por vinte e quatro alunos, sendo quinze do sexo masculino e nove do sexo feminino. A faixa etária destes alunos situa-se entre os doze e catorze anos, tendo a grande maioria treze anos. Todos os alunos desta turma residem no Grande Porto.

De forma geral, a turma apresenta um comportamento adequado ao seu nível etário, podendo ser considerado razoável, demonstrando saber estar e ser, embora em determinados contextos se manifestem um pouco irrequietos e conversadores.

Em relação ao aproveitamento, a turma é bastante heterogénea, revelando a maioria dos alunos métodos e hábitos de estudo e resultados académicos bastante satisfatórios, enquanto que seis alunos apresentam um nível de rendimento baixo.

É de referir ainda que um dos meus alunos com NEE, o Fernando, está diagnosticado com Hiperactividade e Défice de atenção (desde Maio de 2007), sendo revelada a seguinte descrição do mesmo:

\begin{abstract}
"apesar do aluno revelar boas capacidades cognitivas, as áreas da atenção, emocionais, psicossociais do temperamento e da personalidade interferem gravemente no desenvolvimento das competências previstas."
\end{abstract}

\section{Este aluno revela:}

- Comportamento agressivo para com os pares;

- Problemas em responder a solicitações dos professores, por mais simples que sejam, destabilizando as aulas; 
- Dificuldade em manter a sua posição de trabalho por períodos longos de tempo;

- Grande desorganização dos materiais escolares.

O Fernando está grande parte do tempo atento, talvez porque Inglês seja uma das suas disciplinas favoritas ou, como a sua Directora de Turma refere, trata-se dum aluno que tem um elevado QI e, como tal, está desatento apenas no momento de apresentação de conteúdos que entretanto já domina.

Contudo, é notório a sua falta de controle perante a sua impulsividade, já que experimenta uma grande dificuldade em esperar a sua vez numa actividade de grupo, acabando por resultar em tentativas grosseiras de tomar o lugar dos que têm a vez naquele momento. Tento resolver esta situação através de reforços positivos como: "Sei que hoje vais conseguir respeitar a vez dos outros!" ou "Hoje conseguiste respeitar duas vezes a vez dos teus colegas e sei que amanhã vai ser melhor ainda!".

Devido à sua grande necessidade de se mexer, que também não é capaz de controlar, nomeei-o meu assistente, função que leva muito a sério. Tem a seu cargo tarefas como: a preparação do material escolar, ligar/ desligar o retroprojector ou apagar o quadro; a recolha e monitorização do cumprimento dos trabalhos de casa; a solicitação da presença de alguma funcionária na sala de aula, etc.

Tendo em conta o que foi dito anteriormente, podemos assumir, nas palavras de Sanches Ferreira \& Santos (2000, p. 29), que "uma turma não é só o conjunto de crianças seleccionadas, os nomes agrupados no princípio do ano - o Manuel, o João Luís, a Carla, o Abel, a Sofia e os outros -, mas sim um grupo com uma identidade própria construída com a contribuição de todos".

Tendo desmistificado o mito da turma homogénea, analisaremos agora quais os papéis do professor no processo de ensino-aprendizagem, de forma a organizar e gerir a sala de aula com vista a inclusão de toda a diferença presente.

\subsection{Os papéis do professor no processo de ensino-aprendizagem}

Para muitos investigadores, o papel do professor tem um grande significado "para a determinação do sucesso do ensino [...]" que depende da "eficácia do docente" (SANCHES FERREIRA, 1999, p. 18).

Podemos referir que o papel do professor tem como base a autoridade que é inerente à própria função educativa, mas, como sabemos, os alunos transpõem as reacções afectivo-comunicacionais que têm com os membros do seu seio familiar para o próprio processo de ensino-aprendizagem. 
Segundo Harmer (1983), o professor de deve ser "a good technician" e segundo Littlewood(1992) um "a facilitator of learning". Resumidamente, o professor deve, deste modo, ser um organizador, um instrutor, um comunicador e, por último, mas não menos importante, uma fonte de conhecimento.

Tendo em conta esta multiplicidade de papéis, há um outro aspecto que pode condicionar a postura do professor na sala de aula: a expectativa que se cria sobre os alunos. De facto, já aqui falámos de expectativas, mas importa agora discutir até que ponto estas podem influenciar a própria postura do professor na sala de aula e, numa segunda instância, os resultados académicos dos seus alunos. Usando o caso da minha própria turma, foi-me referido no início do ano lectivo que o aluno António seria um excelente aluno, já que os seus pais seriam os dois médicos, e que o Diogo seria muito mal comportado, dado o seu percurso escolar e problemas familiares que tem devido a um dos pais estar desempregado. Como é referido por Sanches Ferreira \& Santos (2000, p. 33), "variáveis como a classe social, o poder económico, a etnia, a estrutura familiar e o percurso escolar, favorecem a criação de estereótipos que vão influenciar as interacções professor-aluno".

Quando tive as primeiras sessões de trabalho com a turma, apercebime de facto do potencial do aluno António, mas não me apercebi do tão grave mau comportamento do aluno Diogo. As representações ao nível cognitivo e comportamental que me transmitiram foram determinantes nas expectativas que desenvolvi para com os referidos alunos, mas segundo as observações que recolhi aula após aula apercebi-me de que o aluno Diogo adorava a disciplina de Inglês, sendo participativo e empenhado ao longo da aula. O facto de estar muito motivado fazia com que, por vezes, não fosse ordenado na participação, atropelando um ou outro comentário do colega, mas uma observação mais cuidada desmentiu de facto a representação estereotipada que me tinham feito acreditar.

Aula após aula, procurei motivar o aluno Diogo a uma participação mais ordenada e com mais qualidade. Possivelmente, porque mudei a minha expectativa inicial, baseada na representação que me tinham feito crer, o aluno Diogo ter-se-á apercebido dessa minha mudança de expectativas para consigo através da minha própria expressão facial, tom de voz e postura (ROSENTHAL \& JACOBSON, 1968:23).

\subsection{A organização do processo de ensino-aprendizagem com vista à inclusão}

De facto, a falha repetida por parte dum aluno pode ser devastadora. De acordo com Winebrenner (1996, p. 49), "once students are convinced that they are incapable of learning, their expectactions of failure often become a selffulfilling prophecy". Neste sentido, importa ao professor criar condições e organizar o processo de ensino-aprendizagem de forma a que o aluno tenha a possibilidade de atingir o sucesso. 
De acordo com Gump (1987), metade dos comportamentos dum professor dizem respeito ao ensino, ou seja, explicações, questões, respostas, feedbacks, etc. A outra metade é referente às tarefas de organização do próprio processo de ensino-aprendizagem, nomeadamente: gestão comportamental de momentos de indisciplina ou desatenção. Também de acordo com a perspectiva de DOYLE (1986, p. 394-395), "classroom teaching has two major task structures organized around the problems of (a) learning and (b) order".

Por sua vez, para Geraldi (2000), a aula é um acontecimento, através do qual se constrói novo conhecimento. Assim sendo, a sala de aula é um "cenário onde os comportamentos de ensino-aprendizagem têm lugar e, como tal, local por excelência de compreensão e aplicação dos fenómenos de aprendizagem" (FERREIRA; SANTOS, 2000, p. 36).

De acordo com Doyle (1986), a sala de aula é, pois, um cenário pedagógico que tem características que influenciam o repertório comportamental dos professores e alunos, nomeadamente: a multidimensionalidade que se prende com a quantidade e qualidade de acontecimentos e a resposta aos mesmos; a simultaneidade, pois os acontecimentos ocorrem ao mesmo tempo, o que implica que o professor tenha que estar atento a uma multiplicidade de ocorrências; a imediaticidade, já que a interacção professor-aluno ocorre de forma tão rápida, que por vezes se torna impossível de controlar todas as interacções; a historicidade, uma vez que a turma tem uma identidade própria que se reconstrói no cenário pedagógico da aula e é espelhada nas rotinas e modos de estar dos alunos; por último, mas não menos importante, a imprevisibilidade que se refere ao facto de ser impossível prever qual o próximo acontecimento ou sua consequência.

Foi precisamente isto que senti quando aconteceu o incidente crítico que passo a descrever. Alguns dos alunos da turma que escolhi como estudo de caso para este trabalho estão constantemente a ser expulsos pelos diferentes professores. Na minha opinião, creio que retirar estes e outros alunos da sala de aula, ainda que temporariamente, é retirar-Ihes também a riqueza da aula e substituí-la por uma situação mais precária. Ao mesmo tempo, está-se a tornar público que estes alunos têm dificuldades abrindo caminho a sentimentos negativos que o podem fragilizar afectiva e cognitivamente. Sinto que, no caso destes alunos, a sua inserção na escola deveria provocar mudanças qualitativas, procurando-se encontrar uma resposta mais exigente e legítima.

Ao analisar uma das minhas primeiras aulas, sinto que talvez não tenha procedido da forma mais correcta ao enviar um dos alunos para o Gabinete de Acompanhamento Disciplinar. ${ }^{3}$ Este aluno estava constantemente a importunar os colegas com observações do que teria feito no dia anterior. A minha reacção deveria ter sido a de tentar encontrar uma articulação possível entre as actividades culturais do aluno e aquelas que constavam do exercício do manual de ensino, pois certamente não constava o Zapaderin, ${ }^{4}$ a famosa dança cigana. Este e os outros alunos precisam claramente de actividades que partam da 
valorização do seu contexto sócio-cultural para espaços de partilha com a cultura do Outro.

Tendo em conta o projecto europeu "InterProject", ${ }^{5}$ em que estive recentemente envolvido enquanto investigador, procurei implementar algumas das estratégias recomendadas pelos resultados dessa investigação, o InterGuide, construído para promover práticas baseadas numa abordagem intercultural e inclusiva. Após esta aula, resolvi pedir a todos os alunos que escrevessem uma autobiografia que incluísse: nome, idade, local de nascimento, línguas que falam, onde cresceram, como cresceram, etc. Qual não foi o meu espanto quando percebi que havia não apenas um ou dois alunos mas sim muitos mais alunos que tinham: pais a viver no estrangeiro; outra língua materna para além do Português; outra nacionalidade para além da Portuguesa. Alguns alunos assinalaram ainda que não gostam da escola pois não têm tempo para brincar e, sobretudo, porque sofrem discriminação. Incluo aqui um dos textos que foi redigido pela aluna cabo-verdiana, a Raquel, pois foi um texto que me fez repensar a minha postura na sala de aula:

\begin{abstract}
"Sou a Raquel e tenho 13 anos. Nasci em Cidade da Praia no Cabo Verde. Vivo com a minha mãe aqui faz algum tempo (7 anos). Gosto de estar aqui. A minha mãe agora tem trabalho. Gosto da minha escola também, mas não gosto das aulas. Os professores estão sempre a chatear-me a dizer que me porto mal! A DT está sempre a pedir-me a caderneta... Só me apetece ficar em casa! O que mais me chateia são as aulas de Francês e Inglês! Os professores falam sobre a família e eu não gosto! Só vivo com a minha mãe ${ }^{6}[\ldots] "$.
\end{abstract}

Através destes incidentes críticos, podemos concluir que Alves (2001, p. 17) tem razão quando apela "Professor: trate de prestar atenção no seu olhar. Ele é mais importante que seus planos de aula.".

Segundo Ainscow et al (1997), "as dificuldades de aprendizagem ocorrem como consequência das decisões tomadas pelos professores, das actividades que propõem, dos recursos que utilizam e das maneiras como organizam a aula". Neste sentido, importa a cada professor perceber de que forma a sua aula está organizada e quais as estratégias eficazes para a criação dum ensino eficaz.

\title{
2.4 O professor eficaz: estratégias eficazes para uma educação eficaz
}

Tendo em conta o olhar reflexivo que temos enquanto professores, debrucemo-nos, agora, sobre quais as estratégias que promovem um ensino mais eficaz. 
Para Kounin (1970), um professor eficaz é aquele que tem salas de aula organizadas, turmas com pouca indisciplina e altos níveis de envolvimento dos alunos em determinada tarefa. Já para ARENDS (1998, p. 52), existem sete características fundamentais para podermos falar num professor eficaz, nomeadamente:

- "With-itness - the ability to see deviant behavior almost before it occurs.

- Overlapping - the ability to attend to different teaching events simultaneously, and deal with a disruption while continuing the lesson

- Smoothness and momentum in lessons - conducting smooth and well-organized lessons without behaviors that interrupt the flow of the lesson or slow the pace

- Group alerting - the ability to keep students "alerted" to the task at hand

- Challenge arousal - the ability to keep students involved and interested in instruction

- Accountability - the ability to keep students accountable for their performance.

- Variety - the ability to vary instruction and learning events."

Neste sentido, podemos referir que um professor eficaz é aquele que consegue: prever um comportamento menos adequado antes dele mesmo acontecer; dar resposta a dois acontecimentos simultaneamente, sem interromper a tarefa principal; apresentar flexibilidade e clareza nas instruções e tarefas propostas; manter o grupo em alerta e constantemente a ser desafiado com busca à construção de novo conhecimento; variar as estratégias propostas; fazer com que os alunos se auto-responsabilizem; e ainda promover estratégias para crianças com necessidades educativas especiais.

Antes de passar para uma análise mais aprofundada da minha postura enquanto professor na sala regular, gostaria de analisar aqui a importância duma das características que considero fundamentais num professor e que prezo enquanto supervisor de estágios pedagógicos de futuros professores do $1^{\circ} \mathrm{Ciclo}$ do Ensino Básico: a clareza nas instruções que existe na interacção verbal em sala de aula.

O grau de utilização de instruções varia de aula para aula bem como de professor para professor. No meu caso, desde que comecei a preocupar-me com o silêncio que existia após a minha proposta de determinada tarefa, resolvi proceder à elaboração de um pequeno questionário de duas questões apenas:

"1 - Percebeste o que o professor pediu para fazer? Justifica.

2 - Conseguiste responder à pergunta sem dificuldade? Justifica." 
Grande parte dos alunos respondeu que sim, mas um terço da turma deu respostas como as que se seguem: "Não percebi porque o professor fala sempre em Inglês" ou "O professor fala muito rápido e quando eu ainda não terminei de passar o sumário, pede logo para olharmos para o acetato".

De facto, mais que em todas as outras disciplinas, é, sobretudo, na aula de LE que os aprendentes recorrem ao silêncio como forma de reacção. De facto, ainda que encarado de forma negativa pelo professor, o silêncio é legítimo se pensarmos que os alunos não entenderam o que Ihes foi solicitado ou instruído.

Como é referido por Vieira (1988, p. 35), "ao nível interactivo, o silêncio constitui um acto de resposta particular, caracterizado pela não tomada de palavra no sentido restrito de produção verbal em situações em que ela deveria ser tomada." No que se refere ao nível pedagógico-comunicativo, o silêncio diagnostica a existência de uma ou mais dificuldades. Desta forma, o silêncio poderá dizer por parte do aluno: "não sei", "não ouvi", "não percebi", "não me apetece responder", etc.

Havendo esta ruptura no processo de interacção, o silêncio vai implicar a emergência de episódios interactivos adaptados, que terão que ser necessariamente sustentados no diagnóstico preciso do problema em causa, o qual apela para uma actividade interpretativa do professor particularmente delicada. Por um lado, a informação da dificuldade não se faz acompanhar de uma informação correlativa das suas causas e consequências. Por outro lado, trata-se dum momento da aula vivido pelo professor com alguma ansiedade, angústia e terror (ARAÚJO E SÀ, 1996, p. 391), como no meu caso, acabando por sentir que teria que fazer algo para mudar a situação.

Neste sentido, o professor que apresenta clareza nas instruções consegue uma maior atenção por parte dos alunos na tarefa que propõe e, consequentemente, os alunos têm mais tempo na tarefa e conseguem melhores resultados académicos. ( SANCHES FERREIRA \& SANTOS, 2000, p. 39). Por sua vez, um professor que apresenta mais comportamentos proactivos, ou seja, que é capaz de antecipar problemas e dificuldades, evita uma maior perda de tempo associada às transições dos momentos de aula.

Analisemos agora que outras variáveis ecológicas influenciam o comportamento do professor e alunos no próprio processo de ensino-aprendizagem.

\subsection{A gestão eficaz da sala de aula numa perspectiva eco-comportamental}

Uma das principais variáveis que precisamos de levar em conta é a ocupação espacial dos alunos ( WHELDDALL \& GLLYN, 1989). De facto, a disposição do cenário pedagógico pode fomentar ou inibir a participação dos alunos ou aumentar e diminuir a disciplina ( STIRES, 1980). 
Sempre que coloco a turma na disposição em círculo verifico que os alunos se comportam de forma menos correcta, uma vez que o seu contacto visual é muito maior entre si. Já quanto a disposição das carteiras em filas, noto que os aprendentes se comportam de forma mais correcta, revelando um maior nível de atenção perante a tarefa proposta.

Para Sanches Ferreira (1991), a atenção do professor pode localizarse frequentemente em determinados lugares da sala, o que faz com que os alunos situados nessas mesmas zonas tenham mais probabilidade de serem quer observados quer interrogados.

No entanto, esta circunstância espacial pode ainda ser gerida pelo professor em termos comportamentais. Os professores que não se situam apenas em frente ao quadro, e que vão percorrendo as diferentes carteiras, de forma a monitorizar as dificuldades e sucessos dos alunos, apresentam uma maior nível de atenção na sala de aula. Também o olhar, a que já aqui nos referimos, pode funcionar como dispositivo de monitorização. De acordo com Cangelosil (1988), "focalizando com regularidade o olhar nos estudantes individuais ou no grupo, o professor comunica a cada um que é parte importante do que se passa na classe".

Sanches Ferreira (1991) corrobora esta tendência, pois mostra que o comportamento dos alunos com piores resultados é influenciado pelo facto de estarem incluídos ou não no campo visual do professor. Na verdade, se pensar nos alunos que tenho na turma deste estudo, verifico que por vezes um olhar mais incisivo de minha parte diminui o risco de mau comportamento, embora alguns destes mesmos alunos mais mal comportados tenham adoptado tipos de comportamento que disfarçam o risco de serem apanhados pelo meu olhar.

Outra variável que se revela muito importante no processo de ensinoaprendizagem é o resultado académico, que também já aqui analisámos anteriormente. Já sabemos que há diferentes ritmos de aprendizagem numa turma e é muito fácil um professor centrar-se num grupo de influência, ou seja, o grupo de alunos que servem de referência ao professor, pois normalmente são aqueles que têm menos problemas de aprendizagem. Para Brophy \& Good (1970), fazer questões a determinados alunos com menos frequência que a outros e dar-lhes menos tempo para a sua resposta pode levá-los a pensar que o professor possa ter uma opinião negativa acerca dos mesmos. Estamos perante um ciclo vicioso já que quanto menor for a aprendizagem por parte dum aluno, menor é a sua exposição ao ensino e, consequentemente, menores as aprendizagens.

Em meados de Novembro, numa das aulas com a turma que analiso neste estudo, resolvi anotar quem chamava para ir ao quadro, a quem questionava, a quem solicitava a opinião, etc. Para meu espanto, reparei que estava a ser influenciado pelo fenómeno do grupo de influência, pois os melhores alunos e aqueles que revelavam atenção eram aqueles que estavam na mira do meu olhar. Concomitantemente, alunos como a Raquel e o Júlio eram aqueles que 
estavam mais sujeitos a críticas relativas ao seu estado comportamental e menos requisitados a participar na sala de aula. Percebi que teria que reflectir acerca desta situação, tendo alterado quer a disposição destes alunos na sala de aula, quer a territorialidade do meu olhar, que passou a ser mais abrangente e atento aos alunos menos solicitados.

\section{O processo de ensino-aprendizagem e a gestão eficaz do tempo de ensino}

Um factor importante para que haja uma boa gestão do tempo de ensino é, sem dúvida, a existência de rotinas, uma vez que são "momentos estruturantes das actividades e dos comportamentos dos alunos" (SANCHES FERREIRA \& SANTOS, 2000:43). Devido aos constrangimentos que, por vezes, uma mudança de actividade acarreta, determinados professores optam por não alterar de estratégia. A não existência de regras de funcionamento leva a uma débil estruturação do tempo.

O tempo no ensino é precioso (CARROLL, 1963) e, como tal, uma das variáveis mais importantes na aprendizagem escolar. Importa estudarmos a melhor forma de gerir o tempo de instrução para conseguirmos níveis de rendimento escolar mais altos.

A quantidade de tempo disponível para a aprendizagem depende de dois grandes factores: o tempo destinado ao ensino e o tempo de envolvimento no ensino. O primeiro refere-se ao tempo estabelecido pelo professor para um determinado tópico ou conceito, ou seja, refere-se às actividades de instrução propriamente ditas. O segundo diz respeito ao tempo que os alunos efectivamente dedicam às tarefas de aprendizagem e é produto da qualidade de instrução.

Para Carroll (idem), a aptidão do aluno para a aprendizagem reflecte não só os níveis de realização possíveis, dentro dos limites de tempo estabelecidos, mas também o tempo necessário para que os critérios de proficiência fixados sejam devidamente alcançados. Contradiz, assim, o modelo tradicional de ensino, que fixa rigorosamente o tempo limite da aprendizagem e admite a normalização dos níveis de desempenho. Neste sentido, o modelo de CARROLL (idem) admite a liberalização do tempo de aprendizagem, de forma a contemplar as diferenças individuais de progressão ( PEIXOTO, 1995, p. 12). O tempo real de aprendizagem depende do empenho do aluno e da oportunidade que este tem de aprender, isto é, do tempo que Ihe é concedido. O tempo necessário à realização da aprendizagem depende da aptidão do aluno, da qualidade da iensino e da capacidade de compreensão dos conteúdos.

Tendo em conta que os níveis de desempenho dependem da proporção entre o tempo real de aprendizagem e o tempo necessário à sua realização, é necessário conceder a cada aluno o tempo que realmente precisa para aprender, através das actividades de remediação dentro da sala de aula ou em regime de aulas de foro complementar. 
Segundo Bloom (1976), todos os alunos aprendem e todos podem ter altos níveis de desenpenho se:

"1) students are given enough time to learn normal information taught in school, and

2) students are provided quality instruction. " (MCILRATH \& HUITT, 1995, WEB).

Para Bloom (1976), ensino de qualidade verifica-se quando o professor: organiza os conteúdos em unidades de aprendizagem flexíveis; desenvolve objectivos específicos para cada unidade curricular; desenvolve medidas avaliativas de natureza formativa e sumativa; e, ainda, planeia e implementa estratégias de grupo, com suficiente tempo de ensino destinado à sua execução, oportunidades de treino e de (re)construção de saberes por parte dos alunos até que estes atinjam o nível desejado de aprendizagem.

A organização do processo de ensino-aprendizagem deve prever uma boa e flexível gestão do tempo de forma a serem aplicadas todas as funções de ensino e dar resposta a todos os ritmos de aprendizagem que temos na sala de aula. Segundo estudos de Good \& Grouws (1979) e Rosenshine \& Stevens (1986), a qualidade de ensino é garantida quando são aplicadas as seguintes funções de ensino numa determinada turma: revisão diária e ensino de itens ainda não totalmente aprendidos; apresentação de novos conteúdos em rápidos mas pequenos passos com explicações e instruções detalhadas; prática guiada em com feedback e correcção; prática individual pelos alunos; revisão semanal e mensal dos conteúdos.

Antes de conhecer estes estudos, as minhas aulas eram estruturadas sempre da mesma forma: correcção dos trabalhos de casa (caso houvesse); activação dos conhecimentos prévios dos alunos acerca do tópico a tratar; apresentação de novos conteúdos; elaboração de exercícios em plenário; marcação de trabalho de casa (se fosse necessário).

Através destas minhas reflexões, sinto agora que as rotinas de sala de aula se alteraram e que os alunos estão muito mais envolvidos nas actividades propostas. Vários alunos, como a Raquel e o Júlio, começaram a participar activamente, respondendo a muitas questões no decorrer da aula, e não apenas quando solicitados. Mais ainda, os alunos estão, a meu ver, mais flexíveis no que se refere à resolução dos exercícios propostos, não os rejeitando e aceitando qualquer desafio.

\section{Conclusões finais}

Neste artigo, procurei caracterizar uma das turmas com as quais tenho o prazer de trabalhar, desconstruindo o mito da homogeneidade/ homogeneização dum grupo de alunos. Parti do pressuposto que a integração é um processo de transformação da escola, suas práticas e seu funcionamento, tendo em conta uma perspectiva inclusiva. 
Enquanto professor, procurei ilustrar como faço a gestão da diferença/ diversidade presente na turma da qual sou titular. Como Barroso $(1999$, p. 89) defende há que passar "da heterogeneidade como problema à heterogeneidade como recurso". Assim sendo, isto é o que procurei fazer, tendo como meta a minha transformação num professor verdadeiramente eficaz, que fosse capaz de: dar instruções claras e precisas; desafiar o aluno na busca incessante de conhecimento e sua (re)construção; promover a responsabilização dos alunos no processo de ensino-aprendizagem; atender aos diferentes níveis e ritmos de aprendizagem presentes na sala de aula; propor estratégias de ensino diversas e adequadas à faixa etária em causa; minimizar comportamentos menos adequados; dar tempo de ensino de qualidade aos alunos para que estes possam desenvolver novas competências.

Segundo Perrenoud (2001, p. 37-38), os professores sonham com uma escola utópica, "com turmas menos numerosas, com uma organização mais flexível das classes e dos graus, com um sistema de avaliação mais individualizado, com uma divisão do trabalho entre as equipes pedagógicas, com programas menos rígidos, com objectivos mais claros". Enquanto isto não é possível, resta ao professor identificar as dificuldades dos seus alunos inseridos em turmas numerosas e de trabalhar com eles de forma a superá-las, promovendo uma gestão eficaz do processo de ensino-aprendizagem.

\section{Referências}

AINSCOW, M.; PORTER, G.; WANG, M. Caminhos para as escolas inclusivas. Lisboa: Instituto Inovação Educacional, 1997.

ALVES, R. A escola com que sempre sonhei sem imaginar que pudesse existir. Porto: Edições Asa, 2001.

ARAÚJO E SÁ, M. Processos de Interacção Verbal em Aula de Francês Língua Estrangeira: Contributos para o Estudo das Actividades Dialógicas de Adaptação Verbal. 1996. Teses de Doutoramento, Universidade de Aveiro, Aveiro,1996.

ARENDS, R. Learning to teach. Boston: McGraw-Hill, 1998.

BARROSO, J. Da cultura da homogeneidade à cultura da diversidade: construção da autonomia e gestão do currículo. In: PORTUGAL. Ministério da Educação (ed.). Forum escola, diversidade, currículo. Lisboa, 1999, p. 79 - 92.

BLOOM, B. Human characteristics and school learning. New York: McGrawHill, 1976.

BROPHY, J.; GOOD, T. Teachers' Communication of Differential Expectations for Children's Classroom Performances: Some Behavioral Data, Journal of Educational Psychology,v. 61, 1970, p. 365-374. 
Mário Rui D. F. da Cruz

CAMACHO, O. Atenção à diversidade e Educação Especial. In: STOBAUS,C.; \& MOSQUERA, J. (Orgs.). Educação Especial: em direcção à Educação Inclusiva. Porto Alegre: EDIPUCRS, 2003.

CANGELOSI, J. Classroom management strategies: gaining and maintaining students cooperation. New York: Paperback, 1988.

CARROLL, J. A model of school learning. Teachers College Record, v. 64, p. 723-733,1963.

DOYLE, W. Classroom organization and management. In: WITTROCK, M. (ed.), Handbook of Research on Teaching. New York: Macmillan, 1986.

GERALDI, J. A aula como acontecimento. Aveiro: Universidade de Aveiro, 2000.

GOOD, T.; GROUWS, D. The Missouri mathematics effectiveness project in fourth-grade classrooms. Journal of Educational Psychology, v. 71, 1979, p. 355-362.

GUMP, P. School and classroom environments. In: STOKOLS, D.; ALTMAN, I. (Eds.). Handbook of Environmental Psychology, v. 1, New York: Wiley, 1987.

HARMER, J. The Practice of English Language Teaching. In Longman Handbooks for Language Teachers. New York: Longman, 1983.

HOLT, J. Teach Your Own. New York: Delacorte , 1981.

KOUNIN, J. Discipline and Group Management in the classroom. New York: Holt: Rinehart \& Winston, 1970.

LITTLEWOOD, W. Teaching Oral Communication. Oxford: Blackwell, 1992.

LYMAN, I. . Not home alone - success of homeschooling movement, 1998. Disponível em: http://findarticles.com/p/articles/mi_m1282/is_n17_v50/ ai_21129273. Acesso em: 12 nov. 2007.

Mcllrath, D.; Huitt, W. The teaching-learning process: A discussion of models. Educational Psychology Interactive. Valdosta, GA: Valdosta State University, 1995. Disponível em: <http://chiron.valdosta.edu/whuitt/papers/modeltch.html..> Acesso em: 14 dez. 2009.

PEIXOTO, E. Aprendizagem de Mestria: mastery Learning e Resolução de Problemas. Lisboa. McGrawHill, 1995.

PERRENOUD, P. A pedagogia na escola das diferenças: fragmentos de uma sociologia do fracasso. Porto Alegre: Artmed, 2001.

ROSENSHINE, B.; STEVENS, R. Teaching functions. In: M. Witrock, M.(Ed.), Handbook of research on teaching. New York: Macmillan, 1986. 
ROSENTHAL, R.; JACOBSON, L. Pygmalion in the classroom: teacher expectation and pupils intellectual development. New York: Holt Rinehart \& Winston, 1968.

SANCHES FERREIRA, M. O tempo na tarefa e o processo de ensino-aprendizagem - estudo observacional de alguns comportamentos do professor e dos alunos. Porto: Universidade do Porto, 1991.

SANCHES FERREIRA, M.; SANTOS, M. Aprender a ensinar: ensinar a aprender. Porto: Edições Afrontamento, 2000.

STIRES, L. Classroom seating location, student grades and attitudes: environment or self-selection?, Environment and Behaviour, 12, 1980.

VIEIRA, I. Interacção verbal e negociação do saber na aula de língua estrangeira. Aveiro: Universidade de Aveiro, 1988.

WHELDDALL, K.; GLYNN, T. Effective classroom learning: a behavioural interactionist approach to teaching. Oxford: Basil Blackwell, 1989.

WINEBRENNER, S. Teaching kids with learning difficulties in the regular classroom: strategies and Techniques every teacher can use to challenge and motivate struggling students. Minneapolis: Free Spirit Publishing, 1996.

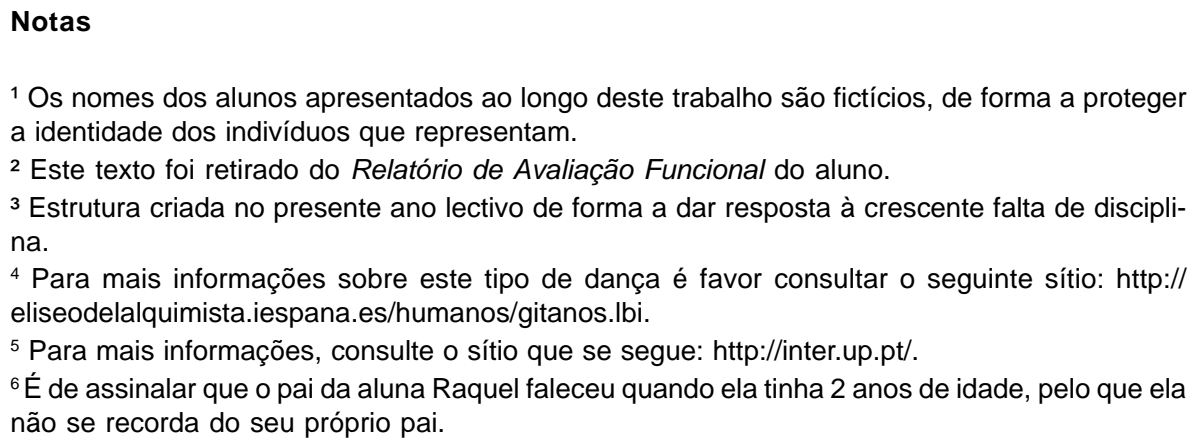

Mário Rui D. F. da Cruz - Avenida Fernando Augusto Oliveira, Sector-6 Lote-8, 3800-540 Cacia, Portugal.

E-mail: mariordfcruz@gmail.com

Recebido em 27 de novembro de 2009

Aprovado em 17 de janeiro de 2010 
